\title{
ESTADO DA ARTE ACERCA DAS ESCOLAS MULTISSERIADAS1
}

\section{RESUMO:}

Maria Angélica Cardoso2

Universidade Estadual de Campinas cardosoangelica@terra.com.br

Mara Regina Martins Jacomeli3 Universidade Estadual de Campinas mararmj@unicamp.br

Este trabalho é parte integrante da pesquisa de Doutorado em Educação, em andamento. Não visamos, nesse momento, apresentar dados analíticos, mas apresentar os primeiros levantamentos relativos à produção científica acerca das escolas multisseriadas. Tema de meu interesse, o projeto nasceu, em 2006, a partir da relação que fiz entre a minha prática docente, em classes multisseriadas, e estudos sobre a organização do trabalho didático em escolas primárias de ensino mútuo. Para sua elaboração, efetuamos um levantamento inicial sobre o tema com a finalidade de averiguar o volume real de estudos e pesquisas relacionados às escolas multisseriadas. $\mathrm{O}$ resultado confirmou nossa hipótese: poucas eram as pesquisas abordando tal objeto. Com o objetivo de mapear a produção referente às escolas multisseriadas iniciamos a primeira fase investigativa com o levantamento da produção. Os trabalhos de identificação e quantificação, ainda que incompletos, permitiram a apresentação de alguns dados preliminares. Salientamos que esse levantamento é parcial e não está finalizado. Porém, é certo que o interesse pelas escolas multisseriadas é muito recente, data dos últimos dezesseis anos: as centenárias escolas multisseriadas, não passam de "adolescentes" objetos de pesquisas.

Palavras-chave: Instituições Escolares, Escolas Multisseriadas, Estado da Arte.

\section{STATE OF THE ART ABOUT THE MULTIGRADE SCHOOLS}

\begin{abstract}
:
This work is constituent of the research $\mathrm{PhD}$ in Education, in course. We do not seek at this moment to present analytical data, but to present the first survey on the scientific production of multigrade schools. Theme of my interest, the project was born in 2006, from the relation among I did my practice teaching in multigrade classes, and studies on the organization of teaching work on primary schools monitorial teaching. For its construction, we performed an initial survey on the subject in order to inquire the actual volume of studies and researches a with regard to multigrade schools. The result confirmed our hypothesis that were few researches approaching this object. In order to map the production about multigrade schools, the first investigative phase started with the production survey. The works identify and quantify, although incomplete, allowed the presentation of some preliminary data. We point out that this survey is partial and not finalized. However, it is certain that the interest in multigrade schools is very recent, and dates of the last sixteen years: the centenary multigrade schools, are merely "adolescent" objects of research.
\end{abstract}

Keywords: Institutions School, Multigrade Schools, State of the Art. 


\section{INTRODUÇÃO}

Este trabalho faz parte da pesquisa de doutorado em andamento no Programa de Pós-Graduação da Faculdade de Educação da UNICAMP. Não visamos, nesse momento, apresentar dados analíticos, uma vez que a investigação está em fase de desenvolvimento, mas apresentar os primeiros levantamentos relativos ao estado da arte acerca das escolas multisseriadas.

A elaboração do projeto teve início em 2006, quando detectamos, em investigações que abordavam a organização do trabalho didático em escolas de ensino fundamental, a baixa produção científica referente às escolas multisseriadas. Tema de meu interesse, o projeto surgiu da relação entre a minha prática docente, em classes multisseriadas, e o estudo da organização do trabalho didático em escolas primárias de ensino mútuo.

Um primeiro levantamento foi realizado com o objetivo de averiguar o volume real de estudos e pesquisas relacionados às escolas multisseriadas. As buscas foram feitas à base do termo escola multisseriada e, como segunda opção, classes multisseriadas, classes unidocentes, escolas isoladas e escolas rurais.

A primeira busca foi realizada no CD do VII Seminário Nacional de Estudos e Pesquisas do HISTEDBR, realizado em Campinas, em julho de 2006,. Esta busca foi ampliada4 e foram encontrados artigos e dissertações que versam sobre temas ligados às escolas multisseriadas, quais sejam: escolas rurais, educação rural, escolas do campo, educação para o campo, escolas unidocentes e classes multisseriadas. No entanto, a maioria desses estudos apenas cita a existência de escolas multisseriadas ou de escolas unidocentes sem, contudo, descrevê-las ou analisá-las; e uma minoria refere-se diretamente ao objeto de nosso interesse, às escolas multisseriadas. A lacuna apontada por Alves (2005) e por Souza e Faria Filho (2006) foi confirmada: são poucas as pesquisas que abordam as escolas multisseriadas.

Segundo Piza e Sena5, (2001, p. 13) as escolas multisseriadas são, historicamente, consideradas como de segunda categoria e, o que é pior, sem alternativa de melhoria; por isso, os educadores e os gestores optaram por esquecê-las, esperando que desapareçam como consequência natural do processo de desenvolvimento das sociedades. Porém, o desaparecimento natural não existe na história, trata-se, sempre, de funções sociais que cumprem ou deixam de cumprir para desaparecerem ou para recriarem. Por essa razão, apesar de todas as mazelas e das políticas de substituição promulgadas desde a década de 1980, as escolas multisseriadas vêm resistindo ao tempo e adentraram o século XXI. Esse fato, no entanto, não se faz presente frequentemente nas pesquisas em história da educação. O tema, pouco explorado, instigou-me a propor o projeto de investigação, aprovado no final de 2007, para ingresso em 2008, no programa da UNICAMP.

Se, no seu nascedouro, as escolas multisseriadas atendiam tanto à população periférica quanto à rural, atualmente, elas se concentram somente na zona rural. Menezes e Santos (2002, p. 2), ao desenvolverem o verbete Escolas Multisseriadas, no Dicionário Interativo da Educação Brasileira6, escrevem que "acredita-se que a educação no campo esteja relegada a segundo plano, limitando-se ao ensino das primeiras letras", afirmando, também, que estas escolas se constituem predominantemente de classes multisseriadas.

Considerando os estudos de Saviani, (1980, p. 197) pode-se deduzir que as escolas rurais não foram criadas para atender aos interesses do homem do campo, mas "a escolarização do campo se revela um fenômeno decorrente da expansão das relações capitalistas no campo". Portanto, as escolas no campo tendem a se efetivar conforme os padrões urbanos, uma vez que a sociedade capitalista se organiza segundo os padrões urbano-industriais. As escolas rurais assumem, assim, um caráter modernizador. É nessa perspectiva que elas são criadas e recriadas. Nesse sentido, explicam-se os argumentos da Revista HISTEDBR On-line, Campinas, número especial, p.174-193, mai.2010 - ISSN: 1676-2584 175 
aparente extinção das escolas multisseriadas e os esforços de superá-las. Porém, apesar do padrão urbano-industrial que delega à escola o formato seriado, graduado, com um professor por série, ainda hoje, as escolas multisseriadas se fazem presentes no cenário educacional brasileiro. Em 2007, eram 93.884 turmas multisseriadas, sendo 19.229 na região norte, 55.618 no nordeste, 11.962 no sudeste, 4.729 no sul e 2.346 no centro-oeste.

Conforme Hage (2006, p. 4), "as escolas multisseriadas, em que pesem todas as mazelas explicitadas, têm assumido a responsabilidade quanto à iniciação escolar da grande maioria dos sujeitos no campo". A partir dessas considerações, buscamos mapear a produção referente às multisseriadas.

Conforme Ferreira, (2002, p. 258) a pesquisas, que se dedicam ao desafio de mapear e de discutir certa produção acadêmica em diferentes campos do conhecimento, são denominadas "estado da arte" ou "estado do conhecimento". Para a autora esse tipo de pesquisa se constitui em dois momentos:

Um, primeiro, que é aquele em que ele (o pesquisador) interage com a produção acadêmica através da quantificação e de identificação de dados bibliográficos, com o objetivo de mapear essa produção num período delimitado, em anos, locais, áreas de produção. [...]

Um segundo momento é aquele em que o pesquisador se pergunta sobre a possibilidade de inventariar essa produção, imaginando tendências, ênfases, escolhas metodológicas e teóricas, aproximando ou diferenciando trabalhos entre si, na escrita de uma história de uma determinada área do conhecimento. Aqui, ele deve buscar responder, além das perguntas "quando", "onde" e "quem" produz pesquisas num determinado período e lugar, àquelas questões que se referem a "o quê" e "o como" dos trabalhos. (FERREIRA, 2002, p. 265).

O que apresentamos nesse trabalho refere-se ao primeiro momento do estado da arte, no qual buscamos respostas somente para as perguntas "quando", "onde" e "quem" produziu pesquisas num determinado período e lugar, cujo objeto foram as escolas multisseriadas. Para tanto, tomamos como fontes básicas a Plataforma Lattes/CNPq, a Biblioteca Digital Brasileira de Teses e Dissertações e o Banco de Teses e Dissertações da Coordenação de Aperfeiçoamento de Pessoal de Nível Superior - CAPES.

\section{MAPEAMENTO DO ESTADO DA ARTE VIA PLATAFORMA LATTES}

A Plataforma Lattes é a base de dados de currículos e instituições das áreas de Ciência e Tecnologia. Conta, atualmente, com cerca de 1.100 .000 currículos, sendo que $31 \%$ são de doutores, mestres e estudantes de pós-graduação e $59 \%$ de graduados e estudantes de graduação7. Buscamos os currículos não pelos nomes, mas por palavraschave, quais sejam: escola/s multisseriada/s, escola/s multiseriada/s8, classe/s multisseriada/s, classe/s multiseriada/s, bisseriada, ensino multisseriado, ensino multiseriado, sala/s multisseriada/s e sala/s multiseriada/s. Foram geradas quinze listas para pesquisadores doutores - primeiro grupo - e quinze listas para os demais pesquisadores (mestres, especialistas, graduados, graduandos e técnicos) - segundo grupo. O primeiro levantamento, para coleta de dados sobre a produção dos doutores, ocorreu em julho e agosto de 2008, sendo atualizado em fevereiro e março de 2009. O levantamento do segundo grupo teve início em setembro de 2009 e, no presente momento (abril/2010), está em processo de revisão e atualização. 
Quanto aos doutores, as quinze listas geradas continham 282 nomes dos quais subtraímos os repetidos, visto que aparecem em várias listas, restando 133 currículos. No decorrer da leitura desses currículos outros 10 foram eliminados por não constar nenhum tipo de trabalho sobre escolas multisseriadas, embora apareçam na busca.

As quinze listas geradas para mestres e demais pesquisadores resultou em 623 nomes, dos quais subtraímos 246 repetidos, restando 377 currículos. Apresentaremos, nesse artigo, os dados referentes às três primeiras listas, o que corresponde a $52 \%$ dos pesquisadores. As três listas são compostas por 197 currículos, dos quais 11 foram eliminados, após a leitura, pois neles nada constava sobre as escolas multisseriadas.

Os currículos que permaneceram foram organizados, primeiramente, sob duas variáveis - relação direta e relação indireta - eleitas a partir da relação do pesquisador com o objeto escolas multisseriadas. A primeira variável considera a relação como direta nos casos em que os pesquisadores estão diretamente envolvidos na pesquisa, seja em projetos docentes, de doutorado, mestrado, especialização, Trabalho de Conclusão de Curso - TCC - e/ou iniciação científica. A segunda, relação indireta, traz os pesquisadores que orientaram, participaram de bancas como examinadores ou participaram de seminários, palestras, oficinas, coordenação de trabalhos, cursos de curta duração, elaboração de projetos, pareceres e artigos, sem que estes estivessem vinculados diretamente às suas pesquisas.

\subsection{ENTRE OS DOUTORES}

Dentre os 123 doutores, 104 foram elencados na segunda variável, relação indireta: 98 pesquisadores estiveram envolvidos em bancas, sendo 10 como examinadores e os outros como orientadores (de doutorado, mestrado, cursos de especialização ou graduação). E 28 estavam envolvidos em outros trabalhos tais como seminários, cursos de curta duração, palestras, oficinas, coordenação de trabalhos, elaboração de pareceres e de artigos. Três pesquisadores estão envolvidos em mais de um item. No grupo de pesquisadores da relação indireta, cabe destacar o número de orientações de TCC: 38, enquanto teses e dissertações totalizaram apenas 6 e 14, respectivamente. As monografias resultantes dos cursos de especialização totalizaram 27 e 3 foram orientações de outra natureza.

Nossa atenção voltou-se para os dezenove currículos cuja relação do pesquisador com o tema se deu de forma direta.

\subsubsection{Pesquisas Docentes}

Os quadros 1, 2 e 3 detalham a distribuição dos trabalhos dos 11 pesquisadores envolvidos em projetos de pesquisa docente. Dentre eles 5 estiveram envolvidos também em orientações vinculadas a seus projetos; 2 projetos (identificados nos quadros por \#) tiveram como produtos apenas trabalhos técnicos: O jogo como recurso didático nas salas multisseriadas (1993) e Elaboração do perfil das turmas multisseriadas do estado de Santa Catarina: as concepções teóricas e manejo de classe (1994). Em 4 currículos (identificados nos quadros por *) os títulos dos projetos não trazem o termo multisseriada/o, mas geraram orientações e/ou artigos a respeito delas. 
Quadro 1 Pesquisas Docente: distribuição por área e linha temática.

\begin{tabular}{|l|c|l|}
\hline \multicolumn{1}{|c|}{$\mathrm{N}^{\mathrm{O}}$} & Área & \multicolumn{1}{c|}{ Linha Temática } \\
\hline 01 & Pedagogia & $\begin{array}{l}\text { Educação no campo: Currículo e Inovação Pedagógica; } \\
\text { Classes Multisseriadas; Políticas de Nucleação }\end{array}$ \\
\hline 02 & Pedagogia & $\begin{array}{l}\text { Educação no campo: Formação docente e práticas } \\
\text { pedagógicas }\end{array}$ \\
\hline$* 03$ & Psicologia Educacional & Ensino de Matemática; Escola Ativa \\
\hline $\begin{array}{l}04 \\
\mathrm{e} \\
05\end{array}$ & Pedagogia & $\begin{array}{l}\text { Educação no campo: Formação Continuada dos Professores } \\
\text { de Classes Multisseriadas }\end{array}$ \\
\hline$\# 06$ & Educação Física & Formação de Professores da Zona Rural \\
\hline$\# 07$ & Psicologia Educacional & Prática docente: concepção de atividade pedagógica \\
\hline$* 08$ & Pedagogia & $\begin{array}{l}\text { Ruralidades: sujeitos, instituições e práticas pedagógicas nas } \\
\text { escolas do campo }\end{array}$ \\
\hline$* 09$ & Pedagogia & Usos sociais de leitura e escrita em comunidades rurais \\
\hline$* 10$ & Filosofia & Formação Inicial de Professores \\
\hline 11 & Psicologia Educacional & Linguagem no processo educativo/escola rural \\
\hline
\end{tabular}

Quadro elaborado por Cardoso, a partir da análise dos currículos/Plataforma Lattes

Embora tenhamos nomeado a segunda coluna do quadro acima como área, nos currículos ela consta como subárea da área Educação, excetuando apenas a Educação Física que consta como área. Pelo exposto nesse quadro verifica-se que a área de produção que ocupa maior espaço nessas 11 pesquisas é a Educação/Pedagogia, com ênfase em educação no campo, com 7 pesquisas. Mas, é a questão da formação do professor e da prática docente o tema amplamente priorizado - 7 pesquisas. Nesse sentido, voltamos a destacar a questão do alto número de TCC orientados pelos pesquisadores no grupo que caracterizamos como relação indireta. Foram 38 TCC dos quais 15 estão voltados para a questão da formação e da prática docente9. Entre os 19 TCC orientados pelos pesquisadores do grupo caracterizado como relação direta, 14 também abordam essas questões. Os outros tratam do currículo, do ensino de Matemática, do processo ensino/aprendizagem, da Pedagogia da Alternância e da organização das classes multisseriadas. Quanto ao $11^{\circ}$ projeto - A importância da linguagem no processo educativo: a escola numa visão rural que, inicialmente, buscou a prevenção dos problemas de aprender, devido às necessidades que se apresentaram ao pesquisador acabou, também, se voltando para a formação docente e sua prática.

Quadro 2 Pesquisas Docente: distribuição por região, período e Instituto de Ensino Superior - IES.

\begin{tabular}{|l|l|c|l|}
\hline $\mathrm{N}^{\mathbf{0}}$ & \multicolumn{1}{|c|}{ Região } & Período & \multicolumn{1}{c|}{ IES ao qual está vinculado o pesquisador } \\
\hline 01 & Norte/PA & $2002-2010$ & Univ. Federal do Pará \\
\hline 02 & Centro-Oeste/MT & $2006-2007$ & Univ. Estadual Paulista Júlio de Mesquita Filho \\
\hline$* 03$ & Nordeste/PE & 2006 & Univ. federal de Pernambuco \\
\hline 04 & Norte/PA & 2006 -atual & Universidade do Estado do Pará \\
05 & & & \\
\hline$\# 06$ & Centro-Oeste/MT & 1993 & Univ. do Estado de Mato Grosso \\
\hline$\# 07$ & Sul/SC & 1994 & Univ. do Sul de Santa Catarina \\
\hline$* 08$ & Nordeste/BA & 2008 -atual & Univ. do Estado da Bahia \\
\hline$* 09$ & Sul/SC & $2006-2007$ & Universidade do Planalto Catarinense \\
\hline$* 10$ & Norte/AM & 2008 -atual & Universidade do Estado do Amazonas \\
\hline 11 & Sudeste/RJ & $1993-1994$ & Universidade Federal Rural do Rio de Janeiro \\
\hline
\end{tabular}

Quadro elaborado por Cardoso, a partir da análise dos currículos/Plataforma Lattes 
Com exceção do item 2, em que a pesquisa desenvolvida em uma instituição paulista aborda um objeto mato-grossense, todas as outras desenvolvem pesquisas cujos objetos são próprios aos estados onde estão instaladas as universidades, conforme mostra o quadro 2. Contudo, priorizamos a região em detrimento das universidades, pois buscamos a pertença dos objetos pesquisados. Dentre eles, 3 pertencem à região norte; 2 ao nordeste; 2 à região centro-oeste; 2 ao sul; e 1 à região sudeste.

Três pesquisas foram produzidas nos anos de 1993 e 1994. Uma (de $n^{\circ} 6$ nos quadros), no estado do Mato Grosso, refere-se à formação continuada de professores das séries iniciais na zona rural, para o trabalho nas turmas multisseriadas. A segunda $\left(\mathrm{n}^{\circ} 7\right)$, no estado de Santa Catarina, realizou uma sondagem para caracterizar o cotidiano escolar dos professores das turmas multisseriadas com relação às suas concepções teóricas sobre atividades pedagógicas. Os autores dessas duas pesquisas não publicaram outros trabalhos relacionados ao tema após a realização dos projetos e elaboração dos trabalhos técnicos. A terceira $\left(n^{\circ} 11\right)$, ao buscar a prevenção dos problemas de aprendizagem, voltou-se para a formação de professores de classes multisseriadas, uma vez que as exigências de atingir, com as classes multisseriadas, o mesmo resultado alcançado com classes seriadas, geravam no professor um processo de culpa-frustração, baixa da auto-estima e desestímulo para o trabalho. Os resultados do trabalho apontaram para a necessidade de "saber trabalhar" com os alunos, sem aplicar modelo "automático ou mecânico". Ou seja, também esta pesquisa acabou se voltando para o tema da formação docente e suas práticas pedagógicas. Embora os registros no currículo desse pesquisador apontem sua participação no projeto, não há registros de nenhuma produção bibliográfica relativa a essa participação.

A maioria dos trabalhos estão nos primeiros anos deste século, como pode ser observado no quadro 2 , contudo os temas continuam privilegiando as questões acerca da formação docente e da prática pedagógica.

Como é sabido, a partir das pesquisas, novos conhecimentos são produzidos, gerando novas publicações. É o que expomos no quadro 9, cujo trabalho de elaboração considerou somente os trabalhos bibliográficos e técnicos cujos títulos, resumos e/ou palavras-chave trazem o termo multisseriada/o.

Quadro3 Pesquisas Docentes: Produções Bibliográficas

\begin{tabular}{|c|c|c|c|}
\hline $\mathrm{N}^{\mathrm{o}}$ & Número de Produções & $\mathrm{N}^{\circ}$ & Número de Produções \\
\hline 01 & 24 & $\# 07$ & 01 \\
\hline 02 & 06 & $* 08$ & 02 \\
\hline$* 03$ & 02 & $* 09$ & 02 \\
\hline 04 & 03 & $* 10$ & - \\
05 & & & \\
\hline$\# 06$ & 01 & 11 & - \\
\hline
\end{tabular}

Quadro elaborado por Cardoso, a partir da análise dos currículos/Plataforma Lattes

\subsubsection{Teses e Dissertações}

Os quadros 4 e 5 apresentam 4 teses e 3 dissertações produzidas por pesquisadores doutores das áreas de: Pedagogia e Psicologia (área Educação), Letras e Ciências Biológicas. São 7 pesquisas, em 3 áreas, abarcando 5 temas, conforme exposto no quadro 4: 
Quadro 4 Teses e Dissertações: distribuição por área e linha temática.

\begin{tabular}{|c|c|c|}
\hline $\mathrm{N}^{\mathrm{o}}$ & TESES & Linha Temática \\
\hline 01 & $\begin{array}{l}\text { Construção da Ação Docente: aprendizagens de professoras } \\
\text { leigas em classes multisseriadas na escola do campo }\end{array}$ & Formação de Professores \\
\hline 02 & $\begin{array}{l}\text { Fundamentos Psicossociais da Formação de Educadores do } \\
\text { Campo }\end{array}$ & Formação de Professores \\
\hline 03 & $\begin{array}{l}\text { Na roça, na raça ... Eu me tornei professor: um estudo sobre } \\
\text { formação docente de professores de classes multisseriadas } \\
\text { no Norte de Minas Gerais e Vale do Jequitinhonha }\end{array}$ & $\begin{array}{l}\text { Métodos e Técnicas de } \\
\text { Ensino }\end{array}$ \\
\hline 04 & $\begin{array}{l}\text { Naquela comunidade, os adultos falam alemão e } \\
\text { "brasileiro". Na escola, as crianças aprendem o português. } \\
\text { Um estudo do continuum oral/escrita em crianças de classe } \\
\text { bisseriada }\end{array}$ & Linguística Aplicada \\
\hline $\mathrm{x}$ & DISSERTAÇÕES & $\mathrm{x}$ \\
\hline 05 & Classes Multisseriadas: que espaço escolar é esse? & Educação Rural \\
\hline 06 & $\begin{array}{l}\text { Concepções de fenômenos naturais em crianças de classes } \\
\text { multisseriadas de escola rural municipal }\end{array}$ & Ensino de Ciências \\
\hline 07 & $\begin{array}{l}\text { Eventos de Letramento em uma Escola Multisseriada de } \\
\text { uma Comunidade Rural Bilíngue (Alemão/Português) }\end{array}$ & Linguística Aplicada \\
\hline
\end{tabular}

Quadro elaborado por Cardoso, a partir da análise dos currículos/Plataforma Lattes

No quadro 5 apresentam-se os dados sobre o período, a região e o Instituto de Ensino Superior - IES - onde a pesquisa foi defendida:

Quadro 5 Teses e Dissertações: distribuição por período, região, período e IES.

\begin{tabular}{|c|c|c|c|c|}
\hline $\mathrm{N}^{\mathbf{0}}$ & Defesa & Região & IES/vínculo do pesquisador & IES/Defesa \\
\hline 01 & 2007 & Norte & UFPA & UFSCAR \\
\hline 02 & 2007 & Sul & UFSC & UFRGS \\
\hline 03 & 2008 & Sudeste & Univ. Est. de Montes Claros & UNIMEP \\
\hline 04 & 1999 & Centro-Oeste & Univ. Fed. Grande Dourados & UNICAMP \\
\hline 05 & 1994 & Sul & UNIVALI & UFSC \\
\hline 06 & 1987 & Sul & UFPR & UFPR \\
\hline 07 & 1997 & Sul & UEM & UNICAMP \\
\hline
\end{tabular}

Quadro elaborado por Cardoso, a partir da análise dos currículos/Plataforma Lattes

Entre as teses e as dissertações também prevalece a área Educação - 4 pesquisas privilegiando o tema formação de professores. A área de Letras e a de Ciências Biológicas também se fazem presentes. Na produção de teses e dissertações, a região sul predomina, sendo que 4 delas foram produzidas na década de 1990 e três nos anos 2000. Apenas dois objetos pesquisados não pertencem à região na qual ocorreu a defesa. Dessas investigações resultaram 18 produções, entre artigos, livros, capítulos de livros e comunicações.

\subsection{ENTRE OS MESTRES E DEMAIS PESQUISADORES}

Entre os mestres e demais pesquisadores, dos 186 componentes das três listas analisadas, 124 estão na variável relação indireta: são 73 orientações; 10 participações em banca como examinadores; 25 publicações (comunicação, artigos, livros e/ou capítulos); e Revista HISTEDBR On-line, Campinas, número especial, p.174-193, mai.2010 - ISSN: 1676-2584 180 
32 trabalhos técnicos (organização de eventos, elaboração de relatórios, elaboração de material didático e pareceres). Alguns pesquisadores estão envolvidos em mais de um item.

Na variável relação direta estão 62 pesquisadores. Dedicamo-nos à análise deste grupo que está assim distribuído: 14 envolvidos em projetos de pesquisa; 14 autores de TCC; 11 autores de monografias; 20 autores de dissertações e 07 autores estão desenvolvendo teses de doutoramento.

\subsubsection{Projetos de Pesquisa} temática:

O quadro 6 apresenta os 14 projetos de pesquisa distribuídos por área e linha

Quadro 6 - Projetos de Pesquisa: distribuição por área e linha temática.

\begin{tabular}{|c|c|c|c|}
\hline $\mathrm{N}^{\mathrm{o}}$ & Área & Projeto & Linha Temática \\
\hline 01 & Letras & $\begin{array}{l}\text { Formação Continuada dos Professores de Classes Multisseriadas } \\
\text { do Campo: um estudo em São Domingos do Capim - PA (2007- } \\
\text { 2008). }\end{array}$ & $\begin{array}{l}\text { Formação de } \\
\text { professores }\end{array}$ \\
\hline 02 & Pedagogia & $\begin{array}{l}\text { Grupo de Estudos e Pesquisa Em Educação Rural na Amazônia/ } \\
\text { Geperuaz. }\end{array}$ & Educação Rural \\
\hline 03 & Pedagogia & $\begin{array}{l}\text { Banco de Dados sobre a realidade educacional da multissérie no } \\
\text { Estado do PA/ Geperuaz. }\end{array}$ & Educação Rural \\
\hline 04 & Gestão Escolar & $\begin{array}{l}\text { Classes Multisseriadas: Desafios da Educação Rural no Estado } \\
\text { do Pará/ Região Amazônica. }\end{array}$ & Educação Rural \\
\hline 05 & Pedagogia & $\begin{array}{l}\text { Classes multisseriadas: desafios da educação rural no Estado do } \\
\text { Pará/ Região Amazônica/ Geperuaz. }\end{array}$ & Educação Rural \\
\hline 06 & Pedagogia & $\begin{array}{l}\text { Grupo de Estudos e Pesquisa em Educação do Campo na } \\
\text { Amazônia/Geperuaz. }\end{array}$ & Educação Rural \\
\hline 07 & $\begin{array}{l}\text { Educação } \\
\text { Ambiental }\end{array}$ & $\begin{array}{l}\text { *Classes Multisseriadas: desafios da educação rural no Estado do } \\
\text { Pará/Região Amazônica desenvolvida pelo Geperuaz } \\
\text { Educação do Campo: uma análise de práticas e experiências da } \\
\text { organização do trabalho pedagógico em classes multisseriadas no } \\
\text { município de Cametá, PA. }\end{array}$ & Educação Rural \\
\hline 08 & $\begin{array}{l}\text { Educação e } \\
\text { Contemporaneida } \\
\text { de }\end{array}$ & $\begin{array}{l}\text { Ruralidades diversas-diversas ruralidades: sujeitos, instituições e } \\
\text { práticas pedagógicas nas escolas do campo, BA. }\end{array}$ & Educação Rural \\
\hline 09 & $\begin{array}{l}\text { Administração } \\
\text { Escolar }\end{array}$ & $\begin{array}{l}\text { Práticas Corporais nas Classes Multisseriadas da Zona da Mata } \\
\text { Sul de Pernambuco }\end{array}$ & Educação Física \\
\hline 10 & Pedagogia & $\begin{array}{l}\text { Educação do Campo na Amazônia Paraense: nucleação e } \\
\text { transporte escolar/ Geperuaz }\end{array}$ & $\begin{array}{l}\text { Educação Rural/ } \\
\text { Nucleação }\end{array}$ \\
\hline 11 & Pedagogia & $\begin{array}{l}\text { Educação do Campo: Fatores de Exclusão de Escolaridade no } \\
\text { Alto Oeste Potiguar } \\
\text { Extensão: Atividade Curricular Em Comunidade - ACC - } \\
\text { Educação do Campo e os Desafios das Classes Multisseriadas. }\end{array}$ & $\begin{array}{l}\text { Educação do } \\
\text { Campo }\end{array}$ \\
\hline 12 & Pedagogia & $\begin{array}{l}\text { Projeto de Pesquisa e Extensão: Construção Coletiva de uma } \\
\text { Proposta Metodológica para o Ensino em Classes Multisseriadas } \\
\text { da Zona Rural de Cajazeiras - PB. }\end{array}$ & $\begin{array}{l}\text { Metodologia de } \\
\text { Ensino }\end{array}$ \\
\hline 13 & $\begin{array}{l}\text { Educação e } \\
\text { Contemporaneida } \\
\text { de }\end{array}$ & $\begin{array}{l}\text { * A Pedagogia das Classes Multisseridas: Um olhar sobre a } \\
\text { prática pedagógica dos professores das classes multisseriadas de } \\
\text { Amargosa } \\
\text { * Ruralidades Diversas-Diversas Ruralidades: Sujeitos, } \\
\text { Instituições e Práticas Pedagógicas nas Escolas do Campo, Bahia }\end{array}$ & $\begin{array}{l}\text { Educação } \\
\text { Rural/Práticas } \\
\text { Pedagógicas }\end{array}$ \\
\hline 14 & Pedagogia & $\begin{array}{l}\text { Avaliação da formação continuada dos professores de classes } \\
\text { multisseriadas do campo: um estudo em São Domingos do } \\
\text { Capim, PA }\end{array}$ & $\begin{array}{l}\text { Formação de } \\
\text { professores }\end{array}$ \\
\hline
\end{tabular}

Quadro elaborado por Cardoso, a partir da análise dos currículos/Plataforma Lattes 
São 5 as áreas - Pedagogia, Educação e Contemporaneidade, Letras, Gestão Escolar e Educação Ambiental - nas quais estão distribuídos os projetos de pesquisas desenvolvidos pelos mestres e outros pesquisadores. São 9 pesquisadores da região norte, todos eles no estado do Pará, e 5 do nordeste: dois na Bahia, 1 em Pernambuco, 1 no Rio Grande do Norte e 1 na Paraíba. Não aparecem mestres e outros pesquisadores envolvidos diretamente em projetos de pesquisas sobre as escolas multisseriadas nas outras regiões brasileiras. Quanto à linha temática, as pesquisas estão concentradas em educação rural focando temas ligados à formação de professores, educação física, metodologia do ensino e práticas pedagógicas. Confirmando que as pesquisas acerca das escolas multisseriadas são muito recentes, temos apenas 1 projeto que foi desenvolvido no final da década de 1990, precisamente em 1998-1999. Todos os outros pertencem a este século.

\subsubsection{Trabalhos de Conclusão de Curso - TCC}

Foram apenas 14 autorias de Trabalhos de Conclusão de Curso. No entanto, entre os pesquisadores, tanto da variável relação direta quanto da relação indireta, contabilizamos mais 113 TCC cujos autores não têm currículum lattes. Nos quadros a seguir, no 7, 8 e 9, apresentamos a distribuição por área, por linha temática, e por região e IES, respectivamente.

Quadro 7 - Trabalhos de Conclusão de Curso: distribuição por área.

\begin{tabular}{|l|l|}
\hline Pedagogia & 63 \\
\hline Normal Superior & 54 \\
\hline Letras & 02 \\
\hline Formação de Professores & 02 \\
\hline Pedagogia da Terra & 02 \\
\hline Ciências Naturais e Matemática & 02 \\
\hline História & 01 \\
\hline Educação Física & 01 \\
\hline
\end{tabular}

Quadro elaborado por Cardoso, a partir da análise dos currículos/Plataforma Lattes

Quadro 8 - Trabalhos de Conclusão de Curso: distribuição Linha Temática

\begin{tabular}{|l|l|}
\hline Leitura (prática, hábitos, dificuldades, formação do leitor) & 21 \\
\hline Professores: formação (9), prática (3), desafios (2) e função(1) & 15 \\
\hline Processo Ensino/Aprendizagem (11) e Desafios (03) & 14 \\
\hline Prática Pedagógica & 13 \\
\hline Classes Multisseriadas & 12 \\
\hline Continuação do Quadro 8. & \\
\hline Dificuldades de Aprendizagem & 11 \\
\hline Nucleação das Escolas Multisseriadas & 05 \\
\hline Programa Escola Ativa & 04 \\
\hline Educação Infantil em Classes Multisseriadas & 04 \\
\hline Dificuldades nas Produções Textuais & 03 \\
\hline Pedagogia da Alternância & 02 \\
\hline Instrumentos e Critérios de Avaliação & 02 \\
\hline Currículo & 02 \\
\hline
\end{tabular}




\begin{tabular}{|l|l|}
\hline Políticas e Propostas Municipais & 02 \\
\hline Representações Sociais & 02 \\
\hline Trabalho com Núcleos Temáticos em Classes Multisseriadas & 01 \\
\hline Invasão Cultural & 01 \\
\hline Alfabetização & 01 \\
\hline Educação Física & 01 \\
\hline Alfabetização de Jovens e Adultos em Classes Multisseriadas & 01 \\
\hline Repetência & 01 \\
\hline O lúdico como estratégia & 01 \\
\hline Poesia na Escola & 01 \\
\hline Experiências de Vida & 01 \\
\hline Gestão Escolar & 01 \\
\hline Ensino de Ciências & 01 \\
\hline Literatura Infantil & 01 \\
\hline Violência na Escola & 01 \\
\hline Desenvolvimento da Lateralidade & 01 \\
\hline Aplicação da Metodologia Interdisciplinar & 01 \\
\hline Quadro elaborado por Cardoso, a partir da análise dos currículos/Plataforma Lattes
\end{tabular}

Quadro 9 - Trabalhos de Conclusão de Curso: distribuição por IES e região

\begin{tabular}{|l|r|}
\hline \multicolumn{1}{|c|}{ Norte } & \\
\hline Univ. do Estado do Amazonas & 50 \\
\hline Univ. do Estado do Pará & 09 \\
\hline Univ. Federal do Pará & 10 \\
\hline Univ. Federal de Rondônia & 12 \\
\hline Univ. Federal do Acre Nordeste & 01 \\
\hline & \\
\hline Univ. do Estado da Bahia & 07 \\
\hline Univ. Estadual do Vale do Acaraú, CE & 02 \\
\hline Univ. Estadual de Feira de Santana & 01 \\
\hline Univ. Federal do Reconcavo Baiano & 01 \\
\hline Univ. Estadual do Sudoeste da Bahia & 01 \\
\hline Univ. Federal do Ceará & 01 \\
\hline Univ. federal do Maranhão & 02 \\
\hline \multicolumn{1}{|c|}{ Sul } & \\
\hline Univ. do Sul de SC & 01 \\
\hline Univ. de Passo fundo, RS & 01 \\
\hline Univ. do Contestado, SC & 02 \\
\hline Univ. do Vale do Itajá́ & 01 \\
\hline Univ. de Santa Cruz do Sul, RS & 02 \\
\hline & \\
\hline Univ. Federal Fluminense, RJ & 02 \\
\hline Univ. Estadual de Montes Claro, MG & 01 \\
\hline Continuação do Quadro 9. & 01 \\
\hline Centro Universitário de Caratinga, MG & 01 \\
\hline Centro Universitário de Patos de Minas, MG \\
\hline \multicolumn{1}{|c|}{ Centro-Oeste } & \\
\hline Fundação Univ. do Tocantins & \\
\hline
\end{tabular}




\begin{tabular}{|l|r|}
\hline Univ. Federal do Mato Grosso & 04 \\
\hline Univ. Estadual do Centro-Oeste & 01 \\
\hline
\end{tabular}

Quadro elaborado por Cardoso, a partir da análise dos currículos/Plataforma Lattes

Em 12 currículos não foi possível identificar a Instituição na qual o TCC foi desenvolvido. O curso de Pedagogia e o Normal Superior são as áreas predominantes. Os temas ligados à leitura, formação de professores, processo ensino-aprendizagem, prática pedagógica, classes multisseriadas e dificuldades de aprendizagem, despontam na preferência dos graduandos. Nesse quesito, a região norte dispara na frente das outras regiões: são $82 \mathrm{TCC}$, enquanto os nordestinos produziram 15, os sulistas 7 , os pesquisadores do centro-oeste 6 e os do sudeste 5. A produção de TCC na década de 1990 fica em apenas 8, enquanto nos anos de 2000 a 2009 foram 119.

\subsubsection{Monografias}

Foram produzidas 11 monografias em 11 cursos de especialização, conforme mostra o quadro 10. Dentre elas 3 estão na região sul e 6 na região norte.

Quadro 10 - Monografias: distribuição por área, linha temática e região.

\begin{tabular}{|c|c|c|}
\hline $\mathrm{N}^{\mathrm{o}}$ & Área (Especialização em) & Linha Temática \\
\hline 01 & $\begin{array}{l}\text { Psicopedagogia } \\
\text { Institucional e Clínica }\end{array}$ & A gestão democrática nas escolas multisseriadas \\
\hline 02 & Supervisão Escolar & $\begin{array}{l}\text { Supervisão Escolar: A Atuação do Supervisor e seu } \\
\text { Relacionamento com os Docentes nas Escolas com Turmas } \\
\text { Multisseriadas }\end{array}$ \\
\hline 03 & $\begin{array}{l}\text { Educação, Cultura e } \\
\text { Organização Social }\end{array}$ & $\begin{array}{l}\text { A organização do Trabalho Pedagógico das Escolas } \\
\text { Multisseriadas em comunidades e vilas ribeirinhas da } \\
\text { Amazônia Paraense. }\end{array}$ \\
\hline 04 & $\begin{array}{l}\text { Gestão Escolar e } \\
\text { Coordenação Pedagógica }\end{array}$ & $\begin{array}{l}\text { A Utilização da Pesquisa Significativa no Contexto das Salas } \\
\text { Multisseriadas das Escolas do Campo. }\end{array}$ \\
\hline 05 & $\begin{array}{l}\text { História da Educação } \\
\text { Brasileira }\end{array}$ & $\begin{array}{l}\text { O processo de nuclearização das escolas rurais multisseriadas } \\
\text { do município de Cascavel, PR. } \\
\end{array}$ \\
\hline 06 & Educação do Campo & $\begin{array}{l}\text { Políticas de Formação Continuada de professores/as de classes } \\
\text { multisseriadas do município de Breves, PA. }\end{array}$ \\
\hline 07 & $\begin{array}{l}\text { Políticas de Gestão e } \\
\text { Financiamento da Ed. }\end{array}$ & $\begin{array}{l}\text { Gestão Democrática no contexto do Programa Escola Ativa: a } \\
\text { experiência no Município de Benevides,PA. }\end{array}$ \\
\hline 08 & $\begin{array}{l}\text { Gestão Estratégica e } \\
\text { Qualidade. }\end{array}$ & $\begin{array}{l}\text { As Classes Multisseriadas, uma Experiência Gestada pela } \\
\text { Secretaria Municipal de Educação de Cametá, PA. }\end{array}$ \\
\hline 09 & $\begin{array}{l}\text { Magistério das Séries } \\
\text { Iniciais }\end{array}$ & $\begin{array}{l}\text { Metodologia do Ensino de Ciências em Escolas } \\
\text { Multisseriadas. } \\
\end{array}$ \\
\hline 10 & $\begin{array}{l}\text { Administração e } \\
\text { Supervisão Escolar }\end{array}$ & Educação Multisseriada e a Família na Escola Getulio Vargas. \\
\hline 11 & Psicologia Educacional & $\begin{array}{l}\text { Condições de aprendizagem na Ilha das Onças, [Belém do } \\
\text { Pará]: as influências de metodologias psico-educacionais } \\
\text { aplicadas ao desenvolvimento de alunos de uma escola com } \\
\text { classe multisseriada. }\end{array}$ \\
\hline
\end{tabular}

Quadro elaborado por Cardoso, a partir da análise dos currículos/Plataforma Lattes

Embora sejam apenas 11 casos, já se pode notar a variedade de cursos de especialização lato sensu. São 11 monografias em 11 cursos diferentes. Apenas 1 tema se repete: a questão da gestão escolar. 
Quadro 11 - Monografias: distribuição por IES e ano.

\begin{tabular}{|c|c|c|}
\hline $\mathrm{N}^{\mathbf{0}}$ & IES & Ano \\
\hline 01 & Univ. Estadual de Santa Cruz & Em andamento \\
\hline 02 & Faculdade de Educação da Serra & 2007 \\
\hline 03 & Univ. Federal do Pará & 2005 \\
\hline 04 & Faculdade Gama Filho & $2008-2010$ \\
\hline 05 & Universidade Estadual do Oeste do Paraná & Em andamento \\
\hline 06 & Univ. Federal do Pará & Em andamento \\
\hline 07 & Univ. Federal do Pará & 2006 \\
\hline 08 & Universidade Cândido Mendes & 2004 \\
\hline 09 & Universidade do Planalto Catarinense & 1995 \\
\hline 10 & Centro Universitário Amparense & 2006 \\
\hline 11 & Universidade do Estado do Pará & 2007 \\
\hline
\end{tabular}

Quadro elaborado por Cardoso, a partir da análise dos currículos/Plataforma Lattes

Além desses 11 pesquisadores/autores, 35 monografias foram orientadas. Dentre elas 12 estão no nordeste, 6 no norte, 6 no sul, 3 no centro-oeste e 2 no sudeste. Em 6 não foi possível identificar a região. Também a produção de monografias se concentra nos anos deste século. Dentre as 46 monografias produzidas e orientadas apenas uma foi concluída em 1995; todas as outras foram realizadas entre 2000 e 2009.

Os temas nas 35 monografias que foram orientadas estão assim distribuídos:

Quadro 12 - Monografias Orientadas: distribuição por área.

\begin{tabular}{|l|r|}
\hline Psicopedagogia & 09 \\
\hline Gestão Escolar & 03 \\
\hline Supervisão Escolar & 03 \\
\hline Práticas Interdisciplinares na Educação Infantil e Educação Infantil & 03 \\
\hline Alfabetização & 02 \\
\hline Metodologia do Ensino Superior & 02 \\
\hline Educação & 02 \\
\hline Coordenação Pedagógica & 02 \\
\hline Políticas do Planejamento Pedagógico & 01 \\
\hline Orientação Educacional & 01 \\
\hline Pedagogia da Educação Infantil e das Séries Iniciais & 01 \\
\hline Educação Básica & 01 \\
\hline Educação Física & 01 \\
\hline Ensino de Matemática & 01 \\
\hline Visão Interdisciplinar & 01 \\
\hline Formação de Professores & 01 \\
\hline Teoria e Metodologia em Educação & 01 \\
\hline
\end{tabular}

Quadro elaborado por Cardoso, a partir da análise dos currículos/Plataforma Lattes

Quadro 13 - Monografias Orientadas: distribuição por linha temática.

\begin{tabular}{|l|c|}
\hline Aprendizagem (processo e dificuldades) & 07 \\
\hline Leitura (dificuldades de leitura e escrita, produção de texto) & 06 \\
\hline Classes Multisseriadas & 03 \\
\hline Programa Escola Ativa & 02 \\
\hline Continuação do Quadro 13. & \\
\hline Nucleação & 02 \\
\hline
\end{tabular}

Revista HISTEDBR On-line, Campinas, número especial, p.174-193, mai.2010 - ISSN: 1676-2584 


\begin{tabular}{|l|r|}
\hline Avaliação & 01 \\
\hline Prática Docente & 01 \\
\hline Estratégias de Ensino & 01 \\
\hline Representações Sociais & 01 \\
\hline Currículo & 01 \\
\hline Salas Multisseriadas e Professores Leigos & 01 \\
\hline Gestão Escolar & 01 \\
\hline Educação Física & 01 \\
\hline Perfil do Aluno & 01 \\
\hline Ginástica Laboral & 01 \\
\hline Sistema de Ensino & 01 \\
\hline Síndrome do Pensamento Acelerado & 01 \\
\hline Práticas de Letramento & 01 \\
\hline Educação Infantil em Classes Multisseriadas & 01 \\
\hline Planejamento Sistematizado & 01 \\
\hline
\end{tabular}

Quadro elaborado por Cardoso, a partir da análise dos currículos/Plataforma Lattes

Confirmando a variedade de cursos lato sensu são 17 áreas. As monografias estão concentradas na área da Psicopedagogia, estando as demais bem distribuídas entre as outras áreas. Os temas relacionados à leitura e à aprendizagem são os recorrentes.

\subsubsection{Dissertações}

Das 20 dissertações produzidas, apenas uma data de 1993. As demais são todas deste século, estando 5 em andamento. As áreas e os temas estão assim distribuídos:

Quadro 14 - Dissertações: distribuição por área.

\begin{tabular}{|l|r|}
\hline Mestrado em Educação & 15 \\
\hline Mestrado em Educação e Contemporaneidade & 02 \\
\hline Mestrado em Educação em Ciências e Matemáticas & 01 \\
\hline Mestrado em Educação: Conhecimento e Inclusão Social & 01 \\
\hline Mestrado em Educação Especial & 01 \\
\hline
\end{tabular}

Quadro elaborado por Cardoso, a partir da análise dos currículos/Plataforma Lattes

Quadro 15 - Dissertações: distribuição por linha temática.

\begin{tabular}{|l|r|}
\hline Trabalho Docente e práticas Educativas & 05 \\
\hline Escolas Multisseriadas & 04 \\
\hline Processo Ensino Aprendizagem & 03 \\
\hline Programa Escola Ativa & 02 \\
\hline Ensino de Ciências & 01 \\
\hline Impacto Cultural & 01 \\
\hline Educação de Jovens e Adultos & 01 \\
\hline Representações Sociais & 01 \\
\hline Indicadores custo-aluno-qualidade & 01 \\
\hline Currículo & 01 \\
\hline
\end{tabular}

Quadro elaborado por Cardoso, a partir da análise dos currículos/Plataforma Lattes

As áreas, pelas quais estão distribuídas as dissertações, incluem-se na modalidade da área educacional. São 3 os temas mais recorrentes: o trabalho docente e práticas educativas; as escolas multisseriadas e o processo ensino-aprendizagem. 
A região nordeste predomina com 7 dissertações produzidas, seguida pelo sul com 6 , o norte com 4 e sudeste com 3 dissertações.

\subsubsection{Teses em andamento}

Dentre os mestres, 7 pesquisadores estão desenvolvendo teses de doutoramento cujo objeto é a escola multisseriada. Os temas estão assim distribuídos:

Quadro 16 - Dissertações: distribuição por linha temática.

\begin{tabular}{|l|r|}
\hline Práticas Pedagógicas & 02 \\
\hline Inovação Pedagógica: Círculos de Cultura e Colaboração entre os alunos & 02 \\
\hline Tempo e Ritmos nas Classes Multisseriadas & 01 \\
\hline Desenvolvimento Profissional da Docência & 01 \\
\hline História das Escolas Multisseriadas & 01 \\
\hline
\end{tabular}

Quadro elaborado por Cardoso, a partir da análise dos currículos/Plataforma Lattes

Dentre eles, 2 estão na Universidade Federal de São Carlos; 2 na Universidade da Madeira, Portugal; 1 na Universidade do Estado da Bahia; 1 na Universidade Estadual Paulista Júlio de Mesquita Filho e 1 na Universidade Estadual de Campinas. Na área Educação atuam 3 pesquisadores, 1 atua na Educação e Contemporaneidade, 1 na Educação Escolar e 2 na área da Ciências da Educação. Os temas estão bem divididos, não havendo prevalência entre eles.

\section{TESES E DISSERTAÇÕES NOS BANCOS DE DADOS}

Conforme informações contidas no site http://bdtd.ibict.br, a Biblioteca Digital Brasileira de Teses e Dissertações - BDTD - tem por objetivo integrar os sistemas de informação de teses e dissertações existentes no país, assim como disponibilizar em todo o mundo, via internet, o catálogo nacional de teses e dissertações em texto integral. Em nossas buscas, tanto na BDTD quanto no Banco de Teses e Dissertações da CAPES e no Sistema Lattes/CNPq, utilizamos palavras-chave conforme consta no primeiro parágrafo do item 2. Na BDTD encontramos apenas 7 trabalhos, todos eles encontrados também no Banco de Teses e Dissertações da CAPES.

O Banco de Teses e Dissertações faz parte do Portal de Periódicos da CAPES/MEC e abriga as teses e as dissertações defendidas junto a programas de pós-graduação do país, a partir de 1987. Os resumos estão disponíveis no site www.capes.gov.br/servicos/bancode-teses. Conforme consta no portal, as informações são fornecidos diretamente a Capes pelos programas de pós-graduação. A ferramenta permite a pesquisa por autor, título e palavras-chave. Nele foram encontrados 49 trabalhos: 07 teses e 42 dissertações, os quais estão distribuídos em sete áreas de ensino e 23 linhas temáticas, conforme demonstrado no quadro 17: 
Quadro 17 - Teses e Dissertações: distribuição por área e linha temática.

\begin{tabular}{|c|l|c|}
\hline \multicolumn{1}{|c|}{ Área } & \multicolumn{1}{|c|}{ Linha Temática } & N $^{\text {Trabalhos }}$ \\
\hline $\begin{array}{c}\text { Educação } \\
\text { 36 trabalhos })\end{array}$ & Prática Docente/Prática Pedagógica & 07 \\
\hline & Processo Ensino/Aprendizagem & 05 \\
\hline & Políticas Públicas da Educação & 04 \\
\hline & Educação de Jovens e Adultos & 04 \\
\hline & Formação de Professores & 04 \\
\hline & Cultura e Currículo & 02 \\
\hline & Relação Pedagógica & 01 \\
\hline & Psicanálise e Educação Inclusiva & 01 \\
\hline & Ensino de Matemática e Avaliação & 01 \\
\hline & Gestão Escolar e Prática Docente & 01 \\
\hline & Planejamento e Avaliação Educacional & 01 \\
\hline & Organização Escolar & 01 \\
\hline & Educação e Meio Ambiente & 01 \\
\hline & Movimentos Sociais & 01 \\
\hline & Transporte Escolar & 01 \\
\hline & Processos e Métodos de Ensino & 01 \\
\hline Educação Especial & Práticas Educacionais Inclusivas & 01 \\
\hline Psicologia Educacional & Formação de Conceitos Científicos & 01 \\
\hline & Programas de Atendimento Comunitário & 01 \\
\hline & Formação de Professores & 01 \\
\hline & Prática Pedagógica & 01 \\
\hline Ciências Sociais/Sociologia & Grupos, Sociedade e Representações Sociais & 01 \\
\hline Ciências e Matemática & Etnomatemática & 01 \\
\hline & Processo Ensino/Aprendizagem & 01 \\
\hline Artes Cênicas & Ensino de Teatro & 02 \\
\hline Linguistica Aplicada & Letramento & 03 \\
\hline
\end{tabular}

Quadro elaborado por Cardoso, a partir do resumo das 49 teses e dissertações.

Pelo exposto no quadro acima, é visível a predominância das pesquisas na área da Educação, o que não representa surpresa, sobressaindo-se ali os trabalhos direcionados a investigações relativas à prática docente - oito pesquisas; tema que, também, está presente na área da Psicologia Educacional. Outro tema recorrente é o concernente ao processo ensino/aprendizagem - 6 pesquisas - presente nas áreas de Educação e Ciências e Matemática. Nesse ranking seguem os temas: formação de professores, políticas públicas da educação e educação de jovens e adultos.

Nos quadros 18, 19 e 20 apresentamos a distribuição das teses e das dissertações por período, região e IES no qual a tese ou a dissertação foi defendida. Consideramos a região como o lócus do objeto pesquisado e, na avaliação dos dados, a priorizamos em detrimento das universidades, pois, como já foi dito, importa-nos a pertença do objeto. 
Quadro 18 Teses e Dissertações: distribuição por período.

\begin{tabular}{|c|c|}
\hline Período & $\mathrm{N}^{\mathrm{o}}$ de Trabalhos \\
\hline $2000-2008$ & 37 \\
\hline $1993-1999$ & 11 \\
\hline 1987 & 01 \\
\hline
\end{tabular}

Quadro elaborado por Cardoso, a partir do resumo das 49 teses e dissertações.

A única pesquisa da década de 1980, uma dissertação defendida na Universidade Federal do Paraná - Concepções de Fenômenos Naturais em Crianças de Classes Multisseriadas de Escola Rural Municipal - foi na área de Educação, seguindo a linha temática Educação Rural/Ensino e Aprendizagem em Iniciação às Ciências e não consta no currículo do pesquisador nenhuma produção científica acerca dela, tampouco ele deu seqüência às investigações relativas às escolas multisseriadas.

Foi na década de 1990 que a produção científica sobre as multisseriadas começou a se efetivar, quase quadriplicando no início deste século. Embora a quantidade, no âmbito geral, seja baixa, o aumento nos anos 2000 foi significativo. Esse crescimento supostamente encontrará explicações nas políticas de municipalização e nucleação implementadas nas últimas décadas.

Em relação aos quadros 19 e 20, embora tenhamos priorizado a região em detrimento das universidades onde as pesquisas foram defendidas, foram poucos os casos de não pertença: das 49 pesquisas apenas 9 não pertencem à região na qual está localizada a universidade; 31 pertencem à mesma região que as universidades onde foram defendidas e 9 não identificaram a região de pertença do objeto.

Quadro 19 Teses e Dissertações: distribuição por IES/Defesa.

\begin{tabular}{|c|c|c|c|}
\hline IES/Defesa & $\mathrm{N}^{\mathbf{o}}$ Trab. & IES/Defesa & $\mathrm{N}^{\circ}$ Trab. \\
\hline Universidade de São Paulo & 05 & Universidade de Brasília & 01 \\
\hline Univ. Estadual de Campinas & 04 & Univ. do Estado da Bahia & 01 \\
\hline Univ. Federal do Piauí & 03 & Univ. Federal da Bahia & 01 \\
\hline Univ. Federal do Paraná & 03 & Univ. Estadual de Londrina & 01 \\
\hline Univ. Federal de Mato Grosso & 03 & Univ. Federal do RN & 01 \\
\hline Univ. Federal do Pará & 03 & PUC/Goiás & 01 \\
\hline Univ. Federal do ES & 02 & PUC/Rio de Janeiro & 01 \\
\hline Univ. Federal do Amazonas & 02 & PUC/Campinas & 01 \\
\hline Univ. Federal do RS & 02 & PUC/São Paulo & 01 \\
\hline Univ. Federal Fluminense & 02 & PUC/Rio Grande do Sul & 01 \\
\hline Univ. Estadual do Centro-Oeste & 02 & Univ. Est. Paulista Júlio Mesquita & 01 \\
\hline Univ. Federal de SC & 01 & Univ. Estadual de Maringá & 01 \\
\hline Univ. Federal de Sergipe & 01 & Univ. Regional de Blumenau & 01 \\
\hline Univ. Federal de São Carlos & 01 & Univ. Metodista de SP & 01 \\
\hline Univ. Federal do Pernambuco & 01 & & \\
\hline
\end{tabular}

Quadro elaborado por Cardoso, a partir do resumo das 49 teses e dissertações.

Considerando a pertença, destaca-se a região sul, com 12 pesquisas. Excluindo-se aquelas que não identificaram o lócus, as outras 28 estão distribuídas de forma similar entre as regiões norte, nordeste, sudeste e centro-oeste, como pode ser observado no quadro 20. 
Quadro 20 Teses e Dissertações: distribuição por região.

\begin{tabular}{|c|c|}
\hline Região & $\mathrm{N}^{\circ}$ de Trabalhos \\
\hline Sul & 12 \\
\hline Norte & 08 \\
\hline Nordeste & 07 \\
\hline Sudeste & 07 \\
\hline Centro-Oeste & 06 \\
\hline Não informada no resumo & 09 \\
\hline
\end{tabular}

Quadro elaborado por Cardoso, a partir do resumo das 49 teses e dissertações.

Partindo dos dados apresentados nesta primeira fase do primeiro momento do estado arte, - quando, onde e quem produziu pesquisas num determinado período e lugar confirmamos nossas afirmações quanto à baixa produção científica acerca das escolas multisseriadas. Identificamos um trabalho isolado em 1987, um pequeno crescimento nos anos de 1990 e uma significativa aceleração nos anos 2000. Os trabalhos encontrados nos dois bancos revelaram que a grande maioria das pesquisas está nos Programas de Mestrado: são 42 dissertações para 7 teses.

\section{BREVES CONSIDERAÇÕES}

Com o objetivo de mapear a produção referente às escolas multisseriadas, iniciamos o trabalho de busca das produções científicas acerca do tema. Delimitamos a abordagem por área, linha temática, período, região e período da produção.

Os trabalhos de identificação e quantificação, ainda que incompletos, permitiram a apresentação de alguns dados preliminares. Quanto à área de produção prevalece a educação e suas subáreas, o que não surpreende. Os temas privilegiados entre os doutores, giram em torno, principalmente, da prática e da formação docentes nas escolas multisseriadas, temas também abordados por um número significativo de TCC e pelas áreas de Psicologia e de Ciências e Matemática. Já entre os mestres e outros pesquisadores, além da prática e da formação docentes, também são recorrentes os temas ligados à leitura e ao processo ensino-aprendizagem nas classes multisseriadas.

Os temas ligados à nucleação são mais recorrentes nas regiões sul e sudeste, enquanto no norte e nordeste este tema é pouco abordado, dando-se preferência aos temas ligados ao Programa Escola Ativa. Na nucleação "as classes multisseriadas são extintas e seus alunos transferidos para escolas pólos onde, então, podem ser agrupados por séries ou ciclos" (TV ESCOLA, PROGRAMA SALTO PARA O FUTURO). No entanto, para as regiões consideradas menos desenvolvidas o MEC/Projeto Nordeste iniciou, em 1998, o processo de implantação da Proposta Escola Ativa. No ano seguinte, com o Programa FUNDESCOLA, essa proposta foi expandida às regiões Norte e Centro-Oeste. A Escola Ativa é

[...] uma proposta metodológica voltada para classes multisseriadas que combina, na sala de aula, uma série de elementos e de instrumentos de caráter pedagógico/administrativo, cuja implementação objetiva aumentar a qualidade do ensino oferecido naquelas classes [as multisseriadas] (TV ESCOLA, PROGRAMA SALTO PARA O FUTURO, PGM 3).

Esse levantamento inicial revelou que as regiões sul e norte dividem o domínio, quanto à produção científica dos doutores: teses e dissertações, sul; pesquisas docentes, 
norte. É interessante observar que nem a região norte nem a sul lideram o ranking do número de turmas multisseriadas. Essa liderança é exercida pelo nordeste, com 55.618 turmas multisseriadas - dados do censo de 2007 - o que corresponde a mais da metade das turmas em todo o território brasileiro. A região norte, que ocupa o segundo lugar, concentra 19.229 turmas; e a região sul vem em quarto lugar, com 4.729 turmas. No entanto, no que se refere à produção entre os mestres e outros pesquisadores, a região norte dispara na frente, seguida de perto pela região nordeste, deixando as outras regiões muito para trás. Isto se explica pelo fato de que, os dois grupos que são atuantes nas pesquisas sobre as escolas multisseriadas estarem, um no Pará e outro na Bahia.

O Grupo de Estudo e Pesquisa em Educação do Campo na Amazônia Paraense GEPERUAZ/UFPA - concentra grande número de graduandos e pesquisadores que realizam estudos e pesquisas sobre a realidade educacional do campo na Amazônia. Na Bahia, o Projeto Ruralidades Diversas - Diversas Ruralidades: sujeitos, instituições e práticas pedagógicas nas escolas do campo congrega pesquisadores e graduandos na investigação das ações educativas que se desenvolvem em diferentes espaços rurais na Bahia e na França.

Poucos foram os pesquisadores que deixaram sua região para realizar suas pesquisas. Na maioria das investigações o objeto pertence à mesma região na qual teve andamento a pesquisa.

É impressionante a diferença entre a quantidade de pesquisadores doutores - 123 e de mestres e outros pesquisadores - 377 - que se dedicam a investigar as escolas multisseriadas. Voltamos a frisar que esse levantamento é parcial.

Ao iniciarmos o artigo evidenciamos que um dos motivos que levou à proposição da investigação sobre as escolas multisseriadas foi a baixa produção a seu respeito. Essa condição foi comprovada de forma superficial na elaboração do projeto de pesquisa e aprofundada nesse momento da investigação. Uma comparação, a título de exemplo, pode ser feita entre os temas escolas multisseriadas e formação docente. A busca na Plataforma Lattes pelo primeiro tema revela 282 currículos de doutores e 623 de mestres e outros pesquisadores, enquanto que, para o segundo, tema são 8.322 doutores e 11.992 mestres e outros pesquisadores.

Nessa fase, constatamos também quão recente é o interesse pelo tema: tem-se um trabalho isolado em 1987, um pequeno aumento na década de 1990 e um crescimento razoável depois de 2000. E, embora contínuas, foram poucas as investigações nesses dezesseis anos. As centenárias escolas multisseriadas, não passam de "adolescentes" objetos de pesquisas.

\section{REFERÊNCIAS}

ALVES, G. L. (2005) O Trabalho Didático na Escola Moderna: formas históricas. Campinas, SP: Autores Associados.

BIBLIOTECA DIGITAL BRASILEIRA DE TESES E DISSERTAÇÕES: http://bdtd.ibict.br/

BRASIL, INEP. Sinopses Estatísticas da Educação Básica de 1997 a 2007. Disponíveis em www.inep.gov.br/censoescolar.

BRASIL, TV ESCOLA. (2001). Programa Salto para o Futuro/Série Escolas Rurais e Classes Multisseriadas. Disponível em www.tvebrasil.com.br/saltoparaofuturo/boletim2001. Acesso em 9/1/2010.

CAPES/MEC. Banco de Teses e Dissertações: www.capes.gov.br/servicos/banco-de-teses 
CNPq. Plataforma Lattes: www.cnpq.br

FERREIRA, N. S. A. (2002). As Pesquisas denominadas "Estado da Arte". Revista Educação e Sociedade, ano XXIII, no 79, agosto/2002. p. 257-272.

HAGE, S. Mufarrej. (2006). A Realidade das Escolas Multisseridas frente às conquistas na Legislação Educacional. In: Anais da 29a Reunião Anual da ANPED: Educação, Cultura e Conhecimento na Contemporaneidade: desafios e compromissos manifestos. Caxambu: ANPED. CD ROM.

MENEZES, E. T; SANTOS, T. H. (2002). "Classes multisseriadas" (verbete). Dicionário Interativo da Educação Brasileira - EducaBrasil. São Paulo: Midiamix Editora. Disponível em www.educabrasil.com.br/dicionario. Acesso em 9/1/2007.

PIZA, F. F; SENA, L. B. (2001). PMG 3 - Escola Ativa. Salto para o Futuro. Disponível em www.tvebrasil.com.br/saltoparaofuturo/boletim 2001. Consulta em 9/1/2007.

SANFELICE, J. L. (2007). História das Instituições Escolares. In O Legado Educacional do Século XX no Brasil. SAVIANI, D. [et al.]. 2 ed. Campinas, SP: Autores Associados.

SAVIANI, D. (1980) Educação: do Senso Comum à Consciência Filosófica. SP: Cortez Editora; Autores Associados.

SOUZA, R. F; FARIA FILHO, L. M. (2006) A Contribuição dos Estudos sobre Grupos Escolares para a Renovação da História do Ensino Primário no Brasil. In VIDAL, D. G. (org.) Grupos Escolares: cultura escolar primária e escolarização da infância no Brasil (1893-1971). Campinas: Mercado de Letras. p. 21-56.

\footnotetext{
${ }^{1}$ Este trabalho foi tema da Comunicação Oral apresentada no VIII Seminário Nacional de Estudos e Pesquisas "História, Sociedade e Educação no Brasil" ocorrido entre os dias 30/06 e 03/07/2009, na FE/UNICAMP focando as pesquisas entre os doutores. Aqui apresenta, também, os dados preliminares das pesquisas entre mestres e demais pesquisadores (especialistas, graduados e graduandos).

${ }^{2}$ Professora das séries iniciais do Ensino Fundamental, especialista em Educação/Formação Docente pela UNIDERP, mestre em Educação pela UFMS, doutoranda do Programa de Pós-Graduação em Educação da Faculdade de Educação/UNICAMP. cardosoangelica@terra.com.br

3 Professora doutora do Programa de Pós-Graduação da Faculdade de Educação/UNICAMP, mestre e doutora em Educação pela UNICAMP.

${ }^{4}$ Realizada nos seguintes veículos: Revista E-Curriculum - PUC/SP; 25 edições da Revista on-line do Histedbr; Anais do VII Seminário Histedbr/2006; Sistema de Publicações Eletrônicas de Teses e Dissertações da PUC/SP (1990-2006); Sistema de Publicações Eletrônicas de Teses e Dissertações da USP (2005 e 2006); Dissertações e Teses defendidas no Programa de Pós Graduação/UNICAMP; Dissertações defendidas na UEM (1993-2006); Reuniões da ANPED (23\%/2001 a 29²006); Dissertações e Teses defendidas na UFRS, na UFSC e na UFPR; Curriculum Lattes/CNPq; 28 edições da Revista Brasileira de Educação/ANPED; 13 edições da Revista Brasileira de História da Educação/SBHE; Anais do I, II, III e IV Congressos da SBHE.

${ }^{5}$ Fernando Ferreira Piza e Lílian Barboza de Sena eram, respectivamente, coordenador e assessora técnica da Proposta Pedagógica Escola Ativa.

${ }^{6}$ Disponível em www.educabrasil.com.br/dicionario da educação/c/2/classes multisseriadas.

${ }^{7}$ Dados colhidos no site da Plataforma Lattes: www.cnpq.br.

${ }^{8}$ Multiseriada/o - termo grafado conforme encontrado nos currículos dos pesquisadores.
} 


\begin{abstract}
${ }^{9}$ Os outros 23 estão assim distribuídos: 6 sobre o processo ensino/aprendizagem; 5 relativos à relação escola multisseriada/comunidade; 3 sobre alfabetização e letramento; 2 sobre leitura e escrita; e organização da classes multisseriadas, supervisão escolar, evasão, ensino de Matemática, invasão cultural, produção de textos e classe hospitalar multisseriada com um trabalho cada. Lembramos que todos os trabalhos têm a escola multisseriada como lócus.
\end{abstract}

Artigo recebido em: 04/04/2010

Aprovado para publicação em: 02/06/2010 